\title{
La comunicación estratégica desde el mercadeo en instituciones educativas *
}

\author{
Strategic Communication Based on Marketing at Educational Institutions
}

\author{
Nancy Grajales-Montoya \\ Magister en Gestión de las organizaciones, Universidad de San Buenaventura \\ Medellín-Colombia, nancy.grajales@usbmed.edu.co \\ Ledy Gómez-Bayona (iD \\ PhD en Administración, Universidad de San Buenaventura, \\ Medellín-Colombia, ledy.gomez@usbmed.edu.co \\ Bladimir Coronado-Ríos \\ Magister en Gestión de las Organizaciones, Universidad Cooperativa de Colombia, \\ Medellín-Colombia, bladimir.coronado@campusucc.edu.co
}

\begin{abstract}
Cómo citar / How to cite
Grajales-Montoya, N.; Gómez-Bayona, L.; Coronado-Ríos, B. (2021). La comunicación estratégica desde el mercadeo en instituciones educativas. Revista CEA, v. 7, n. 13, e1684.

https://doi.org/10.22430/24223182.1684
\end{abstract}

Recibido: 23 de agosto de 2020

Aceptado: 9 de diciembre de 2020

\begin{abstract}
Resumen
La gestión administrativa y académica de las organizaciones educativas ha evolucionado en la comprensión de aspectos comunicacionales que generen relacionamiento. Este estudio compara las tendencias entre las prácticas comunicacionales y las estrategias de mercadeo utilizadas en las Instituciones de Educación Superior (IES) del sector privado en Medellín-Antioquia. Para el análisis se hizo una revisión de literatura clasificada en dos fases: la primera, a partir de algunas bases de datos académicas; y la segunda, desde el análisis de las plataformas digitales de las instituciones en estudio. Los resultados arrojaron que se requieren habilidades comunicacionales que faciliten el acercamiento de las colectividades y rompan las barreras de la distancia, por lo que es importante desarrollar estrategias de mercadeo que estén vinculadas a la planeación organizacional para una acertada toma de decisiones. Se concluyó que las acciones de mercadeo desde la comunicación deben ser más estratégicas e intencionales en los diferenciales del portafolio de las instituciones y, al
\end{abstract}

\footnotetext{
* Este artículo se deriva del proyecto titulado «El mercadeo relacional en educación superior» y ha sido financiado con recursos de la Universidad de San Buenaventura Medellín.
} 
mismo tiempo, la oferta debe ajustarse a las necesidades del sector productivo y de la sociedad para ser competitivos.

Palabras clave: comunicación institucional, relaciones públicas, mercadotecnia, estrategia mercadotécnica, instituciones de enseñanza superior.

Clasificación JEL: M21, M31, M37.

\begin{abstract}
The administrative and academic management of educational organizations has made progress in the understanding of certain communicational aspects that produce engagement. This study compares trends in communication practices and marketing strategies used by several private higher education institutions (HEIs) in Medellín, Colombia. For this analysis, we conducted a literature review divided into two stages: first, we used some academic databases; and, second, we analyzed the digital platforms of the institutions studied here. The results indicate that these organizations require communication skills that enable them to have a close contact with their audience and break the barriers of distance. Therefore, they should develop marketing strategies connected to their organizational plans for adequate decision-making. We conclude that their marketing communication actions should be more strategic and stress differentiating factors in their academic programs. Likewise, their programs should be adjusted to the needs of the productive sector and society in order to be competitive.
\end{abstract}

Keywords: Institutional communication, public relations, marketing, marketing strategy, higher education institutions.

JEL classification: M21, M31, M37.

\title{
1. INTRODUCCIÓN
}

Ante un mundo globalizado, la educación toma un papel fundamental, pues las demandas del mercado laboral exigen competencias de diversas índoles: profesionales, comunicacionales, investigativas, en uso de tecnologías de la información y la comunicación, dominio de varios idiomas, entre otras (Fernández-Huerga, 2019). Así, la calidad de la educación, particularmente de la universitaria, toma un enfoque que busca satisfacer dichas demandas, ya que existen individuos con nuevos gustos, deseos y preferencias, y será responsabilidad de la gestión en las universidades construir portafolios con oferta de valor (James et al., 2019; Chan \& Lin, 2016). Aunado a esto, es importante tener en cuenta las nuevas prácticas comunicacionales que se desarrollan en las demás plataformas sociales - y en general en la web -, visitadas por personas con diferencias sociales, económicas, culturales y educativas, etcétera, lo que conlleva a que las IES deban considerar estas facilidades comunicacionales y las diferencias de los individuos a la hora de divulgar sus portafolios educativos, es decir, entender la psicología del consumidor (Iskhakova et al., 2017; Ayman et al., 2020). Con ello, la comunicación en el entorno digital que desarrollen interna y externamente se genera mediante determinados símbolos, palabras, acciones deliberadas de comunicación y por medio de aquellos elementos y comportamientos que conforman su realidad constante (Aguilera Montoya et al., 2010; Belonovskaya et al., 2020). 
La manera como se establecen planes de mercadeo a escala mundial, principalmente en el sector educativo, ha sido representativo en la identificación de las necesidades de la sociedad (Oplatka \& Hemsley-Brown, 2012; Melchiorre \& Johnson, 2017) y el impacto que se genere a los individuos que integran la comunidad. En Latinoamérica se viene avanzando en sensibilizar a los directivos de la importancia que trae la planeación estratégica que genere valor y comunique acertadamente, pero en países como Colombia este proceso es lento y se requiere una mejor adaptación de equipos de trabajo que se articulen con el mercadeo, afianzar la importancia y los beneficios que representan para la gestión administrativa, y para el caso particular de la educación, los diferentes públicos que hacen parte de la comunidad académica, los cuales necesitan comprender la importancia de una buena calidad del servicio para marcar la diferencia en la transformación del individuo a partir del conocimiento y de los valores que componen el talento humano (Kureshi \& Thomas, 2020).

El mercadeo educativo se desarrolla comunicacionalmente con diferentes canales de publicidad: radio, televisión, páginas web, voz a voz, mercadeo directo, plan referidos, entre otros (Poole, 2017; Marcano Aular et al., 2009). Considerando el abanico de posibilidades que brindan las tecnologías de la información y de la comunicación (TIC), especialmente las plataformas sociales como Facebook, Twitter, YouTube, Instagram, etc., Castro López et al. (2005) afirman que «las TIC nos permiten dar un nuevo giro a la concepción tradicional de la función de comunicar» (p. 51). Teniendo en cuenta el valor que conlleva para el entorno educativo la planeación e implementación de estrategias de mercadeo desde la comunicación de manera asertiva, se planteó la pregunta de investigación: ¿Cuáles son las tendencias comunicacionales y las estrategias de mercadeo utilizadas en las IES del sector privado en Medellín-Antioquia? Se analizaron las tendencias de las prácticas comunicacionales en las estrategias de mercadeo usadas en las seis IES del sector privado de la ciudad que aceptaron la invitación a participar del proyecto que ofrece el programa de Administración de Empresas. Se exploraron y evaluaron sus páginas web, se compararon aspectos relacionados con el mercadeo educativo, la comunicación en el entorno web, el contenido académico, las características del sitio web, la navegabilidad, usabilidad e identidad corporativa.

Se contrastó la información de cada sitio web con la teoría e investigaciones sobre el tema que fueron halladas en el ejercicio de búsqueda de información. Luego se determinaron las tendencias y las dinámicas de las prácticas comunicacionales relacionadas con las estrategias de mercadeo de las IES y cómo éstas han permeado a todos los públicos en sus ejes transversales comunes a la docencia, investigación, extensión y bienestar, enfocados a la oferta del programa de Administración de Empresas en Medellín. Los resultados de esta investigación permiten que las IES evalúen y analicen las estrategias que implementan sus líderes de las áreas de comunicación y mercadeo, si éstas son las más adecuadas, pertinentes, modernas y si están a la vanguardia con las exigencias educativas en el contexto nacional e internacional.

Para las IES, conseguir reconocimiento y posicionamiento en el mercado son objetivos que enmarcan y determinan su sostenibilidad, pero es más importante aún captar el cliente o estudiante respondiendo a sus necesidades específicas, toda vez que éste tiene muy claro qué desea estudiar, cuánto puede pagar, qué horario necesita y qué programas tienen más oferta en el mercado laboral. Así las cosas, y con un significativo número de universidades vendiendo sus programas y aplicando diversas herramientas de comunicación y mercadeo, se genera una competencia por la calidad y la excelencia, fundamentales para el logro de sus metas (Oplatka \& Hemsley-Brown, 2012; Stachowski, 2011). En consecuencia, desarrollar las estrategias de mercadeo en las IES significa tener en cuenta 
que la información sea adecuadamente recibida tanto por los usuarios internos y externos para asegurar buenos resultados y generar una buena imagen y reputación institucional, lo que lleva a tener buenas relaciones con el contexto.

\section{MARCO TEÓRICO}

La transmisión de la información es una actividad compleja, más aún si se habla de aquella que tiene como intencionalidad ofertar los servicios académicos en las universidades. Este ejercicio requiere de estrategias amplias y conocimiento de las necesidades del entorno. Así, Haldane (2015) considera que "está claro que es importante para la universidad comunicar la calidad académica interna a un público más amplio pero que se convierta en parte integrante de esa reputación externa, asegurando que ambas estén estrechamente fusionadas y son totalmente auténticas» (Seccion de conclusiones, párr. 1). Por su parte, Zapata (2000) afirma que el desinterés natural de las IES por desarrollar un marketing competitivo había sido por mucho tiempo el motivo de su crecimiento. Sin embargo, en el presente, esta situación es muy distinta tanto en el entorno nacional como internacional. Ahora la competitividad es un reto que debe asumirse con ideas innovadoras, apropiadas a las necesidades del entorno educativo al que vaya dirigida la oferta académica.

Para Contreras Gómez (2013), el mercadeo educativo es la posibilidad de acompañar a un individuo en su transcurrir académico, con el fin de que éste le sea satisfactorio; desde el momento en el que elije su carrera, atraviesa su proceso de formación profesional y culmina con su quehacer laboral. Esto puede entenderse como la posibilidad que tienen las IES para mejorar cualitativamente los programas que ofertan, aumentar la satisfacción del usuario al recibir educación cualificada y desarrollar ventajas competitivas en el mercado. Las IES venden fundamentalmente el servicio intangible de la educación, cuya necesidad radica en mejorar la calidad de vida, el progreso y el bienestar del individuo y de la sociedad. Desde el mercadeo, la oferta de servicios enfocados en la educación se basa en cinco puntos: intangibilidad, inseparabilidad del servicio de la IES, proporcionar resultados variables que dependen de las condiciones que presenta el contexto y el de las personas involucradas, implicación del usuario directa e indirectamente y crear una relación en el tiempo entre el usuario y la IES. De esta forma, la venta de servicios de educación requiere de una sólida imagen institucional, un grupo de profesionales idóneos, soporte tecnológico actualizado y suficiente, reputación en el campo de la investigación, reconocimiento de egresados exitosos y relaciones internacionales que posibiliten intercambios académicos, entre otras.

Varios estudios (Baños González \& Ramírez Perdiguero, 2004; Fondevila Gascón et al., 2011; Fondevila Gascón et al.,2012; Hilera et al., 2013; Sosa Tota \& Useche Aguirre, 2017; Uribe Saavedra et al., 2013) manifiestan que las IES deben aprovechar todas las ventajas que las TIC proporcionan para atraer a más visitantes y futuros clientes/usuarios y con ello hacer de sus portales web una herramienta de mercadeo educativo que promocione los diversos servicios y brinde información actualizada. Los sitios web de las IES son una de las formas de comunicar y dar a conocer la institución, pero se presentan falencias de diseño o de contenido que se mencionan en la investigación de DíazCuesta Galián y Gaona Pisonero (2014), que las publicaciones, datos y recursos multimediales difundidos en plataformas sociales y páginas web de las universidades públicas en general, no son suficientes. Su comunicación está cargada de datos e información corporativa que se repite en sus manuales y planes institucionales, muchos de ellos descargables en formato pdf. Una forma eficiente 
de administrar estos recursos (imágenes, fotografías, videos, etc.) sería enriquecerlos con mensajes amigables, que creen vínculos emocionales positivos y sean fáciles de retener en la memoria.

Por otro lado, las IES ostentan diversas formas de presentar sus portafolios, algunas con prácticas aún muy tradicionales, otras con avanzada tecnología y con los recursos de la web 2.0 y de las plataformas sociales, ya que cada vez se consultan con mayor frecuencia. Esto puede indicar que la tendencia futura de la sociedad sea la de elevar la cantidad de tiempo que permanece conectada a la red mediante el uso de internet (Hartshorne et al., 2006, 2008; Hu y Soong, 2007; Tubin y Klein, 2007, citados por Álvarez-Álvarez, 2017). En este sentido, el Ranking Web de Universidades, desarrollado por el Laboratorio de Cibermetría del Consejo Superior de Investigaciones Científicas [CSIC], (2018) en España, clasifica a todas las universidades del mundo y muestra el posicionamiento de cada IES diferenciado por continentes, área geográfica y país. Esta clasificación se hace teniendo en cuenta los datos públicos disponibles en la web de la IES, combinando variables y una serie de indicadores cuantitativos que miden: el rendimiento global, la actividad científica, los productos, la relevancia y el impacto del sitio web. En el ranking de las cinco mejores universidades de Latinoamérica se encuentran:

1. Universidad de Sao Paulo (Brasil) - puesto 72 en el mundo.

2. Universidad Nacional Autónoma de México - puesto 128 en el mundo.

3. Universidad Federal de Rio de Janeiro (Brasil) - puesto 239 en el mundo.

4. Universidad Estatal de Campinas (Brasil) - puesto 285 en el mundo.

5. Universidad Federal de Rio Grande del Sur (Brasil) - puesto 362 en el mundo (Ranking web of Universities, 2018).

El posicionamiento para Colombia se encuentra así:

1. Universidad Nacional de Colombia - puesto 629 en el mundo.

2. Universidad de los Andes - puesto 650 en el mundo.

3. Universidad de Antioquia - puesto 812 en el mundo.

4. Pontificia Universidad Javeriana - puesto 1124 en el mundo.

5. Universidad del Rosario - puesto 1720 en el mundo. (Ranking web of Universities, 2018).

En la Tabla 1 se muestra el ranking mundial, latinoamericano y nacional de las IES que son objeto de esta investigación.

Tabla 1. Ranking de las IES objeto de estudio

Table 1. Ranking of the HEls analyzed in this study

\begin{tabular}{lccc}
\hline \multicolumn{1}{c}{ Universidad } & $\begin{array}{c}\text { Ranking } \\
\text { Nacional }\end{array}$ & $\begin{array}{c}\text { Ranking } \\
\text { América Latina }\end{array}$ & $\begin{array}{c}\text { Ranking } \\
\text { Mundial }\end{array}$ \\
\hline Universidad Pontificia Bolivariana (UPB) & 8 & 104 & 2015 \\
Universidad Eafit & 12 & 129 & 2271 \\
Universidad de Medellín (UdeM) & 39 & 425 & 4650 \\
Fundación Universitaria Ceipa (Ceipa) & 102 & 885 & 10369 \\
Universidad Católica Luis Amigó & 106 & 906 & 10635 \\
Institución Universitaria Salazar y Herrera (IUSH) & 171 & 1658 & 17790 \\
\hline
\end{tabular}

Fuente: elaboración propia adaptada de (Ranking web of Universities, 2018). 
De este modo, las IES ofrecen todo un entramado de servicios que van más allá de la satisfacción de lo ofertado, porque involucran el progreso y el mejoramiento de la calidad de vida de la comunidad en la que está inmersa:

El valor que ofrece la universidad a un estudiante, pasa por el valor emocional (etapa de importante desarrollo personal), epistémico con la adquisición de conocimientos, valor social, pues las interacciones con sus otros compañeros y la realización de actividades complementarias enriquecen la etapa universitaria y funcional, pues esperan ver recompensados laboralmente el esfuerzo realizado (Doña Toledo \& Luque Martínez, 2017, p. 20).

Asimismo, Pilco Mosquera (2017) advierte que para que las actividades de investigación, docencia y gestión administrativa logren altísimos niveles de compromiso institucional y de satisfacción. Para ello es fundamental prestar atención a la forma como se usan las estrategias de marketing. Por consiguiente, las IES utilizan diferentes destrezas de información para ofertar sus programas, destacar aspectos diferenciadores y dar valor agregado a las mismas. Cada IES debe enfrentar los retos de la competencia y la alta demanda en la educación universitaria no solo en el ámbito nacional, toda vez que se deben abrir las puertas al mercado internacional y alcanzar, por qué no, un buen puesto en listados del ranking web de universidades. Una práctica muy utilizada en la actualidad es la denominada stakeholders en la que se promueve la imagen institucional por medio de estudiantes presentando videos creados por ellos mismos, editados en formatos normalizados, «que se difunden entre sus potenciales públicos a través de sitios para compartir como YouTube» (Aguilera Montoya et al., 2010, p. 91).

En este orden de ideas, las nuevas formas comunicacionales extienden un abanico de posibilidades que van desde la interacción usuario-página web, comunicación bidireccional, inmediatez y acceso a variedad de contenidos de información multimedial (Li et al., 2016), que además de ofertar los programas, ayudan en el posicionamiento y la reputación de las IES. Por ello, para comprender las estrategias de mercadeo se describen algunos conceptos e ideas en el siguiente apartado.

\section{Comunicación organizacional}

Se comprende la comunicación como aquella que las instituciones establecen y forma parte de sus políticas y su cultura. Por este motivo, para lograr una mayor articulación entre las áreas, conviene que la comunicación sea fluida entre los empleados de diversos grados, como los directores y sus colaboradores, y los gerentes con los demás funcionarios de la institución (Castro, 2016), obteniendo los resultados esperados, trazados en la gestión institucional, o reconociendo aquellos factores y elementos problematizadores para encontrar soluciones efectivas encaminadas al logro de los objetivos institucionales, ya que una organización permanece unida gracias a la comunicación (Montoya-Robles, 2018). A su vez, la comunicación organizacional que se da al interior de una entidad trasciende hacia el entorno en el que se puede percibir la importancia de los valores misionales que luego se difunden para no solo lograr la satisfacción sino tambien el reconocimiento y la construcción de relacionamiento duradero que le genere valor a la organización (Oplatka, 2017).

La comunicación organizacional es un proceso social fundamental. El intercambio de mensajes que van orientados al logro de los objetivos institucionales entre los miembros de un área determinada, pueden impactar a la comunidad externa (el contexto), dependiendo de la forma en la que la 
información se presente y al modo en que esta se recibe, afectando los criterios y las actitudes de las personas involucradas (Fajardo \& Nivia, 2016; Montoya-Robles, 2018; Papic Domínguez, 2019). Esto da sentido a que la comunicación organizacional apunte hacia el logro de la satisfaccion de las necesidades dadas en el contexto con el fin de generar mejores programas académicos y servicios educativos. La comunicación organizacional es vista como un proceso de gran importancia para la transmisión de la información y ayuda a mantener entre los colaboradores buenas relaciones dentro de la organización. Una buena comunicación organizacional posibilita el logro de los objetivos institucionales, pues éstos han sido planeados, desarrollados y evaluados por todas las personas que hacen parte de la institución, quienes se han preparado y han mejorado su desempeño para alcanzarlos (Oplatka, 2018). Esto se refleja tanto interna como externamente, impactando positivamente la imagen de la institución. En otras palabras, la comunicación organizacional se relaciona de diversas maneras con el entorno administrativo, proporcionando información a los demás integrantes de la entidad sobre los objetivos administrativos, cómo lo hacen, cómo afecta a la organización y cómo pueden todos participar eficazmente con el fin de ofrecer servicios de calidad (Oplatka 2017) y promover una imagen positiva que inspire confianza, logrando con ello recibir de la comunidad interna y externa apoyo a su desempeño institucional (Aguilera Montoya et al., 2010; Duche Pérez et al., 2019).

\section{Prácticas comunicacionales}

Partiendo del concepto anterior, es importante comprender lo que significan las prácticas comunicacionales, cómo ayudan a orientar la ejecución estratégica comunicacional de las IES permitiéndoles estar a la vanguardia con las diversas formas de comunicación de las nuevas generaciones locales, nacionales y acordes a las necesidades sociales (Hamid, 2016). Hablar de prácticas comunicacionales en el sector de la prestación de servicios en educación superior no es ningún hallazgo, las teorías y las prácticas ya existen y sobre el tema consta la suficiente doctrina, lo que se pretende es valorar precisamente estas herramientas y su aplicabilidad y efectividad. Las prácticas comunicacionales están inmersas en el discurso y permeadas por el contexto sociocultural. En otras palabras, se edifica en el sentido en las prácticas comunicacionales y en los discursos que se exponen, ya que son «una de las dimensiones fundamentales de lo social y de lo cultural» (Von Sprecher \& Boito, 2010, p. 25). Ahora estas prácticas comunicacionales son usadas por las IES como estrategia de mercadeo para ofrecer a la comunidad sus programas académicos, con una carga implícita de significado que abarca el contexto socio-cultural que en la actual sociedad está ligado a la globalización. Se puede afirmar entonces que las prácticas comunicacionales realizadas en las universidades están altamente formalizadas, estandarizadas, reguladas y ordenadas, por lo que son más predecibles (Von Sprecher \& Boito, 2010). Así es posible mercadear los programas, que además se hace con el apoyo de las TIC como las nuevas formas de comunicación y como estrategia basada en las actuales necesidades sociales.

\section{Mercadeo educativo}

El mercadeo, y especialmente el de servicios, es una estrategia de intercambio en la que se obtiene la satisfacción de una necesidad intangible que no se percibe de forma inmediata. En el caso de la educación, que tiene como propósitos fundamentales la construcción del conocimiento, el avance en la ciencia, la investigación, y todo aquello que implique el mejoramiento de la calidad de vida de una comunidad, y por ende su desarrollo humano, acude a la gestión del mercadeo para indagar 
sobre cuáles son aquellas exigencias del contexto y lograr "los propósitos que la sociedad ha planteado para la educación» (Ospina Díaz \& Sanabria Rangel, 2010, p. 113).

El mercadeo en el entorno académico es construido a partir de estrategias que articulen los diferentes públicos para lograr la máxima satisfacción posible y generar una mayor lealtad en los procesos académicos y administrativos, permitiendo de ésta manera no solo la generación de ventajas competitivas a largo plazo, sino también la proyección de los equipos de trabajo de la institución académica (Gómez-Bayona \& Arrubla-Zapata, 2020).

Se considera que el mercadeo educativo ha venido transformándose para beneficiar la interacción con los diferentes grupos de interés. (Gómez-Bayona \& Moreno López 2018) mencionan que el mercadeo en las universidades genera la oportunidad de interconectar los públicos y construir estrategias en articulación con las verdaderas necesidades de la sociedad, al mismo tiempo el enfoque en mercadeo relacional permite que no solamente se construya identidad en las IES, sino que se genere confianza, satisfacción y lealtad. De otro lado, se puede describir el mercadeo educativo como aquel desarrollo de servicios educativos que buscan satisfacer unas necesidades sociales percibidas mediante la investigación ética y con miras al bienestar del entorno, en la que se han percibido factores económicos, de disponibilidad de tiempo, ubicación geográfica, entre otros. Con ello, se promocionan y/o crean programas que sean más convenientes para la comunidad y la IES (Manes, 2004). Por su parte, Llorente Alonso (2017) lo define como «un elemento, diferenciador y el principal motor de la educación. A demás de captación y fidelización» (Sección de contraportada, párr. 2). Para Zapata (2000), el mercadeo educativo involucra:

Además de los usuarios del servicio educativo (estudiantes), otro grupo muy importante que se denomina los donantes (patrocinadores de las universidades). El intermediario entre los donantes y los estudiantes es la organización educativa, que se constituye en el organizador (gestor del intercambio entre donantes y estudiantes). Para una institución universitaria son importantes los dos grupos referidos y se deben hacer planes de mercadeo diferentes para los mismos (p. 5).

Con lo anterior, el mercadeo universitario posibilita a la IES la creación, ampliación y/o mejoramiento de programas y servicios de formación gracias a un ejercicio investigativo de las necesidades sociales de la comunidad que le rodea. Éstos pueden ser o no de naturaleza comercial, pero siempre deben apuntar hacia el bienestar colectivo (Pérez, 2002, citado por Franco Restrepo \& Arrubla Zapata, 2011). Las IES deben tener en cuenta a la hora de implementar el mercadeo educativo la estrategia del mercadeo mix, que se basa en cuatro componentes fundamentales conocidos como las cuatro p: producto, precio, plaza y promoción que expone Carmelo García (2007): Producto: es lo que una empresa ofrece al mercado para satisfacer las exigencias de los clientes/usuario.

- Precio: es el valor que se le otorga a un producto o servicio y por el que los clientes/usuarios pagan para recibir los beneficios del producto o servicio que adquieren.

- Plaza: es el lugar físico en donde se ofrecen los servicios que puede variar según el nivel de intermediación o subcontratación de servicios complementarios a terceros y según las necesidades de desplazamiento de los usuarios.

- Promoción: es aquella que informa, persuade y recuerda a los clientes/usuarios los beneficios de lo que ofrece, con la intención de ejercer influencia en sus creencias, sentimientos y/o comportamientos. 
Las anteriores características, propias del mercadeo mix, deben combinarse en las IES para identificar los potenciales clientes, pero también para desarrollar estrategias de mejora continua al interior de ellas y así expandir su oferta de servicios de forma planificada y eficiente, adaptándose al entorno competitivo (Doña Toledo \& Luque Martínez, 2017). Del mismo modo es relevante para las instituciones de educación superior el papel que juega el cliente e identificarlo, toda vez que para él se ha incrementado el poder de decisión con las múltiples ofertas multimedia. Como lo indican los autores «esta nueva situación trae consigo la necesidad de desarrollar estrategias comunicativas más eficaces, así como potenciar una comunicación directa e individualizada entre la marca y el cliente, sustentada en una estrategia de marketing relacional» (Martín-Santana et al., 2019), entendiendo como marketing relacional esa necesidad de crear relaciones duraderas entre las partes de interés, tanto internas como externas.

\section{Mezcla de mercadeo}

Kotler y Keller (2012) consideran que el marketing mix es la combinación de herramientas utilizadas por las empresas para alcanzar los objetivos propuestos relacionados con un mercado específico y con ello dirigirse a su público objeto. Vallet Bellmunt y Frasquet Deltoro (2005) se basan en varios autores para dar su definición sobre el mix de mercadeo como:

El conjunto de: variables, instrumentos o herramientas, controlables a disposición del gerente de mercadeo, que se pueden coordinar, manejar, manipular o combinar en un programa de mercadeo, y que tienen los siguientes objetivos: producir, alcanzar o influir sobre la respuesta deseada en el mercado objetivo, lograr los objetivos de mercadeo de la empresa o satisfacer al mercado objetivo ( $p$. 142).

Ahora bien, el mix de mercadeo aplicado al contexto de las IES contempla cinco estrategias: Académica: se refiere a la oferta de programas con base en: las potencialidades del proyecto institucional, el reconocimiento del mercado y las necesidades del contexto. Para ello, se requiere hacer un estudio de mercado y determinar los factores sociodemográficos, las tendencias del mercado laboral, la proyección tecnológica, los criterios de satisfacción, los impactos, etc. Con todo lo anterior se puede idear la oferta de nuevos programas académicos o actualizar con los que se cuenta.

- Mercado meta: es la segmentación del mercado y la categorización de las necesidades y deseos de los clientes que buscan satisfacer y, de esta manera, proyectar a la IES de manera competitiva en el mercado de servicios educativos.

- Posicionamiento: alude al elemento diferenciador y cualificador que hace que la IES sea elegida de entre las demás en el entorno competitivo y que está ligada a la imagen institucional y la percepción que se tiene de ésta.

- Competitividad: busca captar, mantener y aumentar el interés del usuario en el servicio que se oferta. La intención es estar a la vanguardia en las tendencias del mercado, mejorando estratégicamente.

- Oportunidad de servicios/mercados: es donde se identifican las oportunidades de mercado, haciendo los respectivos estudios de riesgos con el fin de evitar el fracaso (Carmelo García, 2007, p. 270). 


\section{METODOLOGÍA}

Esta investigación se basó en un método cualitativo, en el cual se seleccionan principalmente artículos de información verídica sobre dicho tema. La metodología utilizada para este estudio se clasificó en dos fases, la primera a partir de una revisión de literatura teniendo en cuenta los lineamientos de Tranfield et al., (2003) en la planeación de la idea y la estructura de la pregunta para construir adecuadamente informes y tener en medio de este proceso claridad de la información recolectada, y la segunda fase se consolidó a partir de la identificación y búsqueda en las diferentes plataformas web donde las instituciones analizadas presentan la información. Es necesario aclarar que las IES fueron invitadas a participar de este proyecto y las que dieron respuesta positiva estuvieron clasificadas y seleccionadas a partir del reconocimiento con el que cuentan en el ámbito local y nacional, al mismo tiempo por ser instituciones que han avanzado en aspectos de calidad y reconocimiento ante la sociedad.

Con el fin de dar respuesta al planteamiento de Tranfield et al., (2003) al momento de realizar revisión de literatura se deja claridad de:

La pregunta de investigación: a la que se dio respuesta en el proceso de planeación investigativo: ¿Cuáles son las tendencias y las prácticas comunicacionales y las estrategias de mercadeo utilizadas en las IES del sector privado de Medellín-Antioquia? La indagación bibliográfica se hizo teniendo en cuenta que este tema del mercadeo educativo y el aporte en la transformación de la gestión en el sector educativo ha sido poco explorado en el entorno latinoamericano, debido a esto, el nivel de alcance investigativo es exploratorio (Sabino, 1992 p. 43).

Los criterios de inclusión: se seleccionaron aquellos documentos que estuvieran en las bases de datos de Google Scholar, Redalyc, SciELO y Scopus. Asimismo, como criterio para incorporar los documentos en el análisis, estaba que dentro de sus palabras clave registraran el mercadeo educativo, la comunicación, la gestión educativa y la educación, de igual modo que fueran documentos que dentro de su objetivo y sus resultados, aportaran en la comprensión del problema planteado en este documento, de la misma manera que se analizaran instituciones de educación y programas de administración o afines. Los criterios de exclusión: no fueron representativos en este estudio los documentos que mencionaran temas diferentes a mercadeo, comunicación y gestión en educación.

Teniendo en cuenta los lineamientos anteriores, se encontraron diferentes artículos científicos (aproximadamente 65) y se clasificaron finalmente 50 de ellos que daban respuesta a la pregunta planteada: ¿Cuáles son las tendencias y las prácticas comunicacionales y las estrategias de mercadeo utilizadas en las IES del sector privado en Medellín-Antioquia? El paso a paso a seguir para la selección de los 50 artículos finales fue:

1. La claridad del objetivo del artículo y que estuviera en la línea del problema de investigación.

2. Que el artículo estuviera publicado en revista reconocida en las bases de datos clasificadas para este estudio.

3. Que los resultados de los artículos fueran significativos y aportaran al planteamiento de este artículo.

4. Que dieran apoyo a la construcción y el desarrollo de objetivo de este artículo. 


\section{RESULTADOS}

En este apartado se muestran los resultados alcanzados después de realizar el análisis de la revisión de literatura clasificada y de hacer el comparativo y la evaluación de los portales de internet de las seis universidades seleccionadas para este ejercicio de investigación. Los aspectos comparados fueron: contenido de la información, características de la interfaz del portal web y la usabilidad de este. Para Hassan et al., (2004), la escritura hipertextual se debe pensar en el tipo de personas que visitan el portal con el fin de adoptar un vocabulario y tono acorde a ellos. También el texto requiere de precisión, creatividad, concisión y estructura.

En la Tabla 2 se observa como resultado que todas las universidades evaluadas presentan información clara en cada uno de los aspectos relacionados con el programa que ofertan. Sin embargo, la IUSH no expone los objetivos de su pregrado de administración. Lo que puede ser una desventaja competitiva en comparación con las demás y que puede afectar negativamente la decisión de matricularse de un individuo que esté interesado en dicho pregrado.

Tabla 2. Comparativo del contenido de la información de un programa específico-Administración de Empresas Table 2. Comparison of contents about a specific program: Business Administration

\begin{tabular}{lccccc}
\hline \multicolumn{1}{c}{ Universidad } & $\begin{array}{c}\text { Misión del } \\
\text { programa }\end{array}$ & Presentación & Objetivos & $\begin{array}{c}\text { Campos de } \\
\text { acción }\end{array}$ & $\begin{array}{c}\text { Malla } \\
\text { curricular }\end{array}$ \\
\hline $\begin{array}{l}\text { Universidad Católica Luis } \\
\text { Amigó }\end{array}$ & $\mathrm{X}$ & $\mathrm{X}$ & $\mathrm{X}$ & $\mathrm{X}$ \\
\hline $\begin{array}{l}\text { Institución Universitaria } \\
\text { Salazar y Herrera }\end{array}$ & $\mathrm{X}$ & $\mathrm{X}$ & $\mathrm{X}$ & $\mathrm{X}$ \\
\hline Universidad de Medellín & $\mathrm{X}$ & $\mathrm{X}$ & $\mathrm{X}$ & $\mathrm{X}$ & $\mathrm{X}$ \\
\hline Universidad EAFIT & $\mathrm{X}$ & $\mathrm{X}$ & $\mathrm{X}$ & $\mathrm{X}$ & $\mathrm{X}$ \\
\hline Universidad CEIPA & & $\mathrm{X}$ & $\mathrm{X}$ & $\mathrm{X}$ & $\mathrm{X}$ \\
\hline $\begin{array}{l}\text { Universidad Pontificia } \\
\text { Bolivariana }\end{array}$ & $\mathrm{X}$ & $\mathrm{X}$ & $\mathrm{X}$ & $\mathrm{X}$ & $\mathrm{X}$ \\
\hline
\end{tabular}

\section{Características del sitio web}

Khoshtaria et al., (2020) hacen saber que dentro de las condiciones de estructurar marca organizacional se deben tener en cuenta aspectos como la identidad y transformación que pueden estar inmersos en aspectos digitales que apoyan en la accesibilidad de los usurios o clientes. Como resultado en este aspecto y para evaluar las características del sitio web fueron tenidos en cuenta los aspectos relacionados con:

Legibilidad en los textos: tipo y tamaño de letra, espacio que ocupa cada elemento del portal, contraste de colores, efectos de tipografía para dar énfasis a la información, aumento y disminución de la resolución de la pantalla, coherencia, claridad y calidad de los textos.

Accesibilidad y navegación (usabilidad): se basa en la norma internacional sobre normas de accesibilidad para el contenido web (Web Content Accessibility Guidelines - WCAG) 2.0, de World Wide Web Consortium [W3C], (2009), que promueve estos niveles de orientación: 
- Principios: robusto, perceptible, comprensible y operable.

- Pautas: presentar información y datos, teniendo en cuenta accesibles a usuarios con diversas discapacidades.

- Criterios de conformidad: descripciones de compras, diseño, compras, regulación o convenios contractuales.

- Técnicas suficientes y recomendables: son informativas y buscan los criterios de conformidad.

Unidad visual y arquitectura web: el contraste entre fondo y texto debe permitir la lectura y las combinaciones de colores deben considerar a aquellos visitantes con discapacidades visuales relacionadas con la percepción del color. El portal debe ser siempre coherente en comparación con sus micrositios, proporcionando consistencia visual (Hassan et al., 2004). Adicionalmente, debe consolidarse la identidad corporativa en el contraste de colores utilizados en el sitio web.

Menú principal vs. Información del programa: los menús de navegación deben ser reducidos, se recomienda que los ítems no sean superiores de nueve, ya que esto supera la acción memorística del cibernauta (Hassan et al., 2004).

Imágenes: son significativas para atraer la atención de quienes visitan el sitio, deben cumplir con un propósito o intención (se describe algo). Deben cuidarse especialmente las características de resolución y tamaño, teniendo en cuenta los aspectos de accesibilidad que describe la W3C (2009). Con lo anterior, se presentan en la Tabla 3 y Tabla 4 los resultados extraídos de la comparación de las características de los seis portales web de las universidades seleccionadas.

Tabla 3. Resultados del comparativo de las características de los portales web de las IES evaluadas Table 3. Results of the comparison of features of the web portals of the HEls evaluated here

\begin{tabular}{|c|c|}
\hline Característica & Hallazgos \\
\hline $\begin{array}{l}\text { Legibilidad en los } \\
\text { textos }\end{array}$ & $\begin{array}{l}\text { Todas las IES evaluadas cumplían con los elementos de este ítem en cuanto a coherencia, } \\
\text { claridad, calidad de la información, así como tipo y tamaño de letras adecuados. }\end{array}$ \\
\hline Accesibilidad & $\begin{array}{l}\text { Según lo descrito por la W3C (2009), ninguno de los portales ofrece opciones personalizables } \\
\text { pensadas para los usuarios con diversos tipos de discapacidades, como por ejemplo la posibilidad } \\
\text { de cambio de colores. } \\
\text { Algunas características personalizables encontradas fueron: en la UdeM. hay una opción de } \\
\text { cambio de idioma español - inglés y la UPB permite aumentar y/o disminuir el tamaño de la letra. }\end{array}$ \\
\hline $\begin{array}{l}\text { Unidad visual y } \\
\text { arquitectura }\end{array}$ & $\begin{array}{l}\text { - Unidad visual agradable a la vista en todas las IES. } \\
\text { - } \quad \text { Se observa identidad corporativa relacionada con los colores. } \\
\text { - } \quad \text { isminución en la resolución de la pantalla de IUSH y Ceipa, mostraron falta de } \\
\text { - } \quad \text { Visualización de iconos de las plataformas sociales (Facebook, YouTube, Twitter, etc.) } \\
\text { solo en Eafit y IUSH. } \\
\text { No se ofrece servicio de chat en ninguno de los portales evaluados en su página } \\
\text { principal. }\end{array}$ \\
\hline $\begin{array}{l}\text { Menús vs. } \\
\text { Información del } \\
\text { programa }\end{array}$ & $\begin{array}{l}\text { Las universidades IUSH y Ceipa permiten una fácil exploración de los contenidos que hacen que su } \\
\text { navegabilidad sea directa, sin redundar en submenús y clics adicionales y accesan a la información } \\
\text { específica del programa. }\end{array}$ \\
\hline Imágenes & $\begin{array}{l}\text { Todos los portales web presentan imágenes adecuadas, con proporciones de resolución y } \\
\text { pixelación. Proporcionan armonía con los demás elementos del sitio, no se presenta sobrecarga } \\
\text { en ellas. Están bien logradas, cumplen con un propósito y motivan al desarrollo personal. }\end{array}$ \\
\hline
\end{tabular}
Fuente: elaboración propia. 
Tabla 4. Comparativo de las características del sitio web Table 4. Comparison of website features

\begin{tabular}{|c|c|c|c|c|c|}
\hline Universidad & $\begin{array}{l}\text { Legibilidad en } \\
\text { los textos }\end{array}$ & $\begin{array}{l}\text { Accesibilidad y } \\
\text { usabilidad }\end{array}$ & $\begin{array}{l}\text { Unidad visual } \\
\text { y arquitectura } \\
\text { de la página }\end{array}$ & $\begin{array}{c}\text { Menú } \\
\text { principal vs } \\
\text { información } \\
\text { del programa }\end{array}$ & Imágenes \\
\hline $\begin{array}{l}\text { Universidad Católica Luis } \\
\text { Amigó }\end{array}$ & $x$ & & $x$ & & $x$ \\
\hline $\begin{array}{l}\text { Institución Universitaria } \\
\text { Salazar y Herrera }\end{array}$ & $x$ & $x$ & & $x$ & $x$ \\
\hline Universidad de Medellín & $x$ & & $x$ & & $x$ \\
\hline Universidad EAFIT & $x$ & & $x$ & & $x$ \\
\hline Universidad CEIPA & $x$ & $x$ & & $x$ & $x$ \\
\hline $\begin{array}{l}\text { Universidad Pontificia } \\
\text { Bolivariana }\end{array}$ & $x$ & & $x$ & & $x$ \\
\hline
\end{tabular}

\section{Tendencias de las prácticas comunicacionales en el mercadeo educativo}

En las tendencias de comunicación se tiene como resultado que el auge de las TIC debe integrarse al mercadeo educativo

Y es que la Universidad no sólo ha de aprovechar las oportunidades técnicas y de otro tipo que le presenta su medio social, sino también y sobre todo acomodarse a él-por ejemplo, a las formas en que nos relacionamos, así como a las vías que permiten acceder al conocimiento (Aguilera Montoya et al., 2010, p. 98).

Esto no es más que las prácticas comunicacionales que están íntimamente ligadas al ámbito de lo cultural y lo social, tienen que ver con la forma como las personas se relacionan e interactúan, permeadas precisamente de tales esferas (Oplatka \& Hemsley-Brown, 2007). Además, los contextos sociales y culturales están afectados por diversos elementos e imaginarios que a su vez le transforman. En consecuencia, los elementos estarían ligados a las TIC y los imaginarios serían la formación de profesionales altamente competitivos y cualificados. Es tarea de las IES unir estos dos componentes en sus estrategias de mercadeo educativo, utilizando las TIC y haciendo realidad los imaginarios planteados.

Precisamente las TIC, que están inmersas en la comunicación, deben ser orientadas hacia las nuevas formas de mercadeo y las IES deben usarlas como aliadas para ir a la par con los cambios de esta sociedad globalizada y superar los desafíos que se les exigen. Así las cosas, la producción y divulgación de ideas, información, conocimiento, entre otras, puede ser una estrategia competitiva que las universidades pueden implementar para fortalecer su marketing (Aguilera Montoya et al., 2010). De esta manera, a la hora de desarrollar su mercadeo educativo, las universidades deben tener en cuenta los elementos que permean a sus potenciales clientes/usuarios: interculturalidad, necesidades, motivaciones, tendencias, exigencias, innovación, inclusión, comportamientos, emociones, elementos diferenciadores, valor agregado, etcétera, que se reflejan en los comentarios que éstos hacen en las diversas plataformas sociales, dejando allí plasmada su percepción sobre un 
producto o servicio, así como un impacto negativo (habrá que evaluar) o positivo, que se traduce en una oportunidad competitiva para atraer nuevos clientes. Lo que equivale a decir que hay que entender la psicología del consumidor para conocer cómo se relacionan con el contenido de la página que exploran (consumo).

Teniendo en cuenta el contenido de los sitios web, y especialmente los de las universidades, es fundamental que éste sea claro, comprensible y conciso. El micrositio de un programa académico debe brindar información sobre la misión, sus objetivos, la malla curricular y el campo de acción, entre otras, siendo este contenido de fuente propia y original, esto quiere decir que no se encuentre en otros sitios web. Además, debe tener características como: legibilidad de los textos, accesibilidad, navegación, unidad visual, arquitectura de la página (menú, imágenes, etc.) (Olvera-Lobo \& AguilarSoto, 2011). Generalmente, las personas que buscan información sobre programas académicos lo hacen porque están interesados, pero buscar en la web puede ser frustrante para algunos cibernautas. Por eso es importante prestar atención a los aspectos relacionados con:

1. Lenguaje preciso, breve y sencillo.

2. Contenido de calidad, actualizado y multimedia (imágenes, video, audio).

3. Número de clics de respuesta (usabilidad).

4. Imagen corporativa definida.

5. Títulos, subtítulos, listado de viñetas y textos cortos.

6. Ortografía y énfasis de palabras claves en negrilla o diferente color para atraer al usuario.

7. Colores de contraste y de fondo.

8. Tamaño y tipo de letra.

9. Organización de la información pensada para que el usuario navegue fácilmente en el sitio web.

Con todo lo anterior, las tendencias de las prácticas comunicacionales en el mercadeo educativo apuntan a una estrategia basada en la web, ya que es allí donde predomina la información de toda índole, y es en la mayoría de las ocasiones el primer recurso que se utiliza para satisfacer una necesidad de información.

\section{DISCUSIÓN}

Los hallazgos del estudio muestran que la gestión de mercadeo desde la comunicación en las instituciones educativas ha venido transformándose para ser asertivos en los medios comunicacionales y en el mensaje que se espera difundir a los públicos; sin embargo, es necesario una mejor planeación estratégica e intencional para que las acciones tengan un mayor impacto, ya que como mencionan Oplatka y Hemsley-Brown (2007), solamente en la planeación y la gestión de mercadeo se podrán ejecutar acciones que generen valor en la comunidad. También se deben tener en cuenta los docentes como eje estratégico que permita una mejor comunicación entre las estrategias que plantean las instituciones y la manera como se socializan en las aulas de clase. Los docentes necesitan intencionalmente ser involucrados en algunas acciones para generar confianza, satisfacción y lealtad en los entornos académicos y de gestión, esto finalmente permitirá un mejor indicador de fidelización en los procesos institucionales y un mayor aporte en la reputación universitaria (Gómez-Bayona et al., 2020). 
Asimismo, los portales web analizados permiten identificar que las estrategias de mercadeo desde la comunicación son similares en el concepto que quieren mostrar a los públicos y en el lenguaje que utilizan para ser claros y oportunos con el tipo de usuarios que llegan a las instituciones, pues los cambios generacionales han modernizado los esquemas de gestión, generando una cultura de comunicación abierta y cercana (Olvera-Lobo \& Aguilar-Soto, 2011). La producción de contenido en las instituciones se ha vuelto más frecuente (Aguilera Montoya et al., 2010), pero poco se profundiza en la fundamentación y claridad que deben tener para ser asertivos con las ideas y los canales utilizados. Es éste el diferencial del artículo: mostrar el impacto que genera la información cuando es cuidadosamente construida y estratégicamente diseñada para los diferentes entornos académicos y empresariales.

Se espera, a partir de los análisis realizados, aportar a las áreas de mercadeo en la manera como se construye comunicación de manera estratégica e intencional con los públicos para que se comprenda el mensaje de la información, como lo hacen notar (Gómez-Bayona et al., 2020) en la consolidación de acciones que involucren a los docentes para generar cultura de mercadeo en las instituciones educativas y que se gestione adecuadamente desde lo académico y administrativo para articular a los directivos en la apuesta de servicio educativo de calidad, como lo expresan (Oplatka \& HemsleyBrown, 2012).

Dentro de las implicaciones prácticas que tiene este estudio, como se ha mencionado a lo largo de las conclusiones y de los resultados, es la importancia de generar sensibilización en las áreas de mercadeo y en los directivos académicos para incorporar el relacionamiento, la comunicación y las estrategias como una cultura que genere conocimiento y valor en aspectos de mercadeo educativo y de reputación universitaria.

\section{CONCLUSIONES}

Luego de esta investigación se concluye que las universidades han tomado decisiones en beneficio a la comunicación del portafolio de productos que ofrece, han incorporado estrategias mercadológicas que favorecen la visibilidad de las IES y al mismo tiempo genera un posicionamiento importante para construir competitividad; por ejemplo, se evidencia que un sitio web que cumple con todos los aspectos mencionados en este artículo, tiene mayores probabilidades de obtener credibilidad y asertividad en la oferta de los programas académicos, por lo que una primera impresión tiene mucho valor para el usuario de la actual sociedad de la información. Con relación a la usabilidad, es bueno reconocer que cada una de las IES evaluadas presentan características diferentes relacionadas con la cantidad de facultades que poseen, así como el número de programas que ofertan, afectando la forma como se diseñó la página web y, por ende, sus menús y submenús de navegación.

En este estudio no se encontró una IES ideal con relación a las características abordadas, ya que cada una tiene sus propias fortalezas, así como aspectos por mejorar. En la actual sociedad de la información es fundamental que las IES promuevan un buen canal de comunicación en su portal web, con una ruta clara a los programas y su oferta institucional, pero sin perder su papel social fundamental que es el de la educación de calidad.

Finalmente, los cibernautas requieren que la información se presente organizada y clara, para que sea comprensible y coherente, pues una navegación cargada de enlaces puede desorientar al 
visitante alejándolo del principal objetivo con el que ingresa a la plataforma. Aspectos como los cambios generacionales hacen que los individuos de hoy, llamados millennials y centennials, requieran la información al instante, con claridad y buen desarrollo. Es así como la gestión de las universidades se ha vuelto representativa desde la comprensión de las necesidades de estos individuos para ser oportunos y pertinentes con lo que se ofrece y la manera como se comunica en los diferentes entornos presenciales y digitales.

Las universidades desde su gestión están en la necesidad de ofertar un portafolio amplio y diverso acorde con los requerimientos sociales del entorno y en procura de dar a conocer la calidad del servicio brindado, por tanto, una comunicación asertiva genera beneficios y es representativa en el mercadeo educativo, su efectividad se ve reflejada si permea contextos socioculturales en el ámbito nacional e internacional. En la prestación de servicios educativos es fundamental que el cliente "estudiante» - la eminente competencia - exige a las IES conservar su calidad, innovar e implementar un sistema de información que divulgue con claridad la información.

Ofertar programas de educación va más allá de una promesa de calidad, las instituciones de educación superior se enfrentan en su día a día con el reto de llegar a todos los públicos y cumplir con sus expectativas implementando estrategias que incluyan el proyecto educativo institucional, las tendencias comunicativas, un enfoque claro con el mercado específico y las oportunidades que ofrece la misma competencia.

Posicionar la marca, y que ésta genere recordación, es el objetivo de toda organización cuando se vende un intangible como la educación. Para lograrlo es imprescindible innovar y acudir a las técnicas de comunicación e información sin olvidar las estrategias enseñadas por los expertos como lo son planificar, organizar, ejecutar y controlar.

En este estudio se evidenció, a través de la revisión de diversos autores, que a medida que evolucionan las estrategias de mercadeo y las prácticas comunicacionales, las IES, igualmente, están a la vanguardia en la aplicación de estas teorías en procura de un buen servicio y del cubrimiento de las expectativas a las partes de interés, pero especialmente en publicar y dar a conocer los esfuerzos de cada institución por perdurar en el mercado.

Un buen plan de mercadeo en la promesa de educación debe incluir a estudiantes y sus familias, aspirantes, egresados, intermediarios o patrocinadores, y que la información dada sea transparente, acorde a la realidad social.

Con el desarrollo de esta investigación se espera aportar al mercadeo educativo desde una mirada comunicacional, y lograr así que se comprenda la importancia que esta disciplina tiene para la gestión de las organizaciones académicas; al mismo tiempo, en el caso latinoamericano, este documento puede ofrecer a la literatura del mercadeo educativo una mirada más contextualizada a la realidad de lo que ocurre en países como Colombia.

\section{CONFLICTOS DE INTERÉS}

Los autores declaran que no presentan conflictos de interés financiero, profesional o personal que pueda influir de forma inapropiada en los resultados obtenidos o las interpretaciones propuestas. 


\section{CONTRIBUCIÓN DE AUTORES}

Para el desarrollo de este proyecto todos los autores han realizado una contribución significativa especificada a continuación:

Nancy Grajales-Montoya: encargada de soportar la estructura introductoria del documento, de la misma manera aspectos teóricos y de análisis de resultados.

Ledy Gómez-Bayona: aportó al engranaje metodológico y datos teóricos que fortalecieran los temas principales, de la misma manera aspectos de los resultados y conclusión del documento.

Bladimir Coronado-Ríos: se encargó de identificar aspectos del entorno comunicacional-educativo y el aporte a la problemática presentada en el documento.

\section{REFERENCIAS}

Aguilera Montoya, M.; Farias Batlle, P.; Baraybar Fernández, A. (2010). La comunicación universitaria. Modelos, tendencias y herramientas para una nueva relación con sus públicos. Revista ICONO14 Revista Científica De Comunicación y Tecnologías Emergentes, v. 8, n. 2, 90-124. https://doi.org/10.7195/ri14.v8i2.248

Álvarez-Álvarez, C. (2017). ¿Qué me ofrecen las páginas web de los centros educativos? estudio exploratorio en Cantabria (España). REICE. Revista Iberoamericana sobre Calidad, Eficacia y Cambio en Educación, v. 15, n. 3, 49-63. https://doi.org/10.15366/reice2017.15.3.003

Ayman, U.; Kaya, A. K.; Kuruç, Ü. K. (2020). The Impact of Digital Communication and PR Models on the Sustainability of Higher Education during Crises. Sustainability, v. 12, n. 20, 8295. https://doi.org/10.3390/su12208295

Baños González, M.; Ramírez Perdiguero, F. J. (2004). Análisis de la competencia en las páginas web de las Universidades. Revista ICONO14 Revista Científica De Comunicación y Tecnologías Emergentes, v. 2, n. 1, 87-97. https://doi.org/10.7195/ri14.v2i1.448

Belonovskaya, I. D.; Matvievskaya, E. G.; Saitbaeva, E. R.; Ksenofontova, A. N.; Usmanov, S. M.; Zatsepina, M. B.; Bakshaeva, E. V. (2020). Digital Communication in Educational Process: Development Trends and New Opportunities. Online Journal of Communication and Media Technologies, v. 10, n. 2, e202008. https://doi.org/10.29333/ojcmt/7928

Carmelo García, M. (2007). Marketing universitario: conceptos y herramientas de marketing aplicadas a la educación superior en España (Tesis de grado). $\underline{\mathrm{URL}}$

Castro López, J.; Celeste, P.; García Abad, L. (2005). Comunica: lecturas de comunicación organizacional. Netbiblo.

Castro, A. (2016). Manual práctico de comunicación organizacional. Editorial Verbum. 
Chan, S. J.; Lin, J. W. (2016). Aiming for Better Employment: A Holistic Analysis from Admission to Labour Market. Journal of Higher Education Policy and Management, v. 38, n. 3, 282-296. https://doi.org/10.1080/1360080X.2016.1174405

Contreras Gómez, M. C. P. (2013). Mercadeo en educación: elementos para una propuesta pertinente (Tesis de Maestría). $\underline{\text { URL }}$

Díaz-Cuesta Galián, J.; Gaona Pisonero, C. (2014). Creatividad e innovación en el espacio universitario. Asociación Cultural y Científica Iberoamerican.

Doña Toledo, L.; Luque Martínez, T. (2017). Relación entre marketing y universidad. Revisión teórica y propuesta de un modelo teórico y de marketing 3.0. Revista de Estudios Empresariales. Segunda Época, n. 2, 2-27. https://doi.org/10.17561/ree.v0i1.3189

Duche Pérez, A. B.; Gutiérrez Aguilar, O. A.; Paredes Quispe, F. M. (2019). Satisfacción laboral y compromiso institucional en docentes universitarios peruanos. Revista Conrado, v. 15, n. 70, 1524. $\underline{U R L}$

Fajardo, G. C.; Nivia, A. M. (2016). Relaciones públicas y comunicación organizacional: ejes de la comunicación "guía de conceptos y saberes». Fundación Universidad de Bogotá Jorge Tadeo Lozano.

Fernández-Huerga, E. (2019). The labour demand of firms: an alternative conception based on the capabilities approach. Cambridge Journal of Economics, v. 43, n. 1, 37-60.

https://doi.org/10.1093/cje/bey013

Fondevila Gascón, J. F.; Carreras Alcalde, M.; Olmo Arriaga, J. L. (2012). Impacto de las tecnologías de la información y la comunicación en la elección de universidad: el caso de internet y las redes sociales. Revista Electrónica de Tecnología Educativa, n. 39.

https://doi.org/10.21556/edutec.2012.39.378

Fondevila Gascón, J. F.; Del Olmo Arriaga, J. L.; Sierra Sánchez, J. (2011). Universidades privadas, ¿̇un subsistema diferente?: cómo desarrollan los estudiantes sus preferencias hacia la universidad. Vivat Academia, n. 114, 277-310. https://doi.org/10.15178/va.2011.114.277-310

Franco Restrepo, J. G.; Arrubla Zapata, J. P. (2011). Marketing en universidades. Descripción, análisis y propuestas. En Memorias del XVI Congreso Internacional de Contaduría, Administración e Informática. Ciudad de México, México. URL

Gómez-Bayona, L. T.; Moreno López, G. A. (2018) El capital relacional y la gestión académica conectados desde la economía. Opción. Revista de Ciencias Humanas y Sociales, v. 34, 239-269. $\underline{U R L}$

Gómez-Bayona, L.; Moreno-López, G.; Machuca-Villegas, L. (2020). La gamificación en mercadeo educativo como estrategia de gestión en las universidades acreditadas. Revista Ibérica de Sistemas e Tecnologias de Informação, n. E34, 336-349. URL 
Gómez-Bayona, L.; Arrubla-Zapata, J. P. (2020). Evolución del mercadeo en el sector universitario. Revista Venezolana de Gerencia, v. 25, n. 89, 159-173. https://doi.org/10.37960/revista.v25i89.31388

Haldane, J. (2015). Los estudiantes en el corazón de la formación universitaria. En J. Mora (Coord.), Reputación de Universidades (15-23). Ediciones Universidad de Navarra.

Hamid, S. A. (2016). Positive and negative perceptions on school marketing: A case study of three types of school in England. International Journal of Academic Research in Business and Social Sciences, v. 6, n. 11, 224-232. http://dx.doi.org/10.6007/IJARBSS/v6-i11/2387

Hassan, Y.; Martín Fernández, F. J.; lazza, G. (2004). Diseño web centrado en el usuario: usabilidad y arquitectura de la información. Hipertext.net, n. 2. $\underline{U R L}$

Hilera, J. R.; Fernández, L.; Suárez, E.; Vilar, E. T. (2013). Evaluación de la accesibilidad de páginas web de universidades españolas y extranjeras incluidas en rankings universitarios internacionales. Revista Española de Documentación Científica, v. 36, n. 1. https://doi.org/10.3989/redc.2013.1.913

Iskhakova, L.; Hoffmann, S.; Hilbert, A. (2017). Alumni loyalty: Systematic Literature Review. Journal of Nonprofit \& Public Sector Marketing, v. 29, n. 3, 274-316. https://doi.org/10.1080/10495142.2017.1326352

James, C.; Crawford, M.; Oplatka, I. (2019). An Affective Paradigm for Educational Leadership Theory and Practice: Connecting Affect, Actions, Power and Influence. International Journal of Leadership in Education, v. 22, n. 5, 617-628. https://doi.org/10.1080/13603124.2018.1481536

Khoshtaria, T.; Datuashvili, D.; Matin, A. (2020). The impact of brand equity dimensions on university reputation: an empirical study of Georgian higher education. Journal of Marketing for Higher Education, v. 30, n. 2, 239-255. https://doi.org/10.1080/08841241.2020.1725955

Kotler, P.; Keller, K. L. (2012). Dirección de marketing (14a ed.). Pearson Educación.

Kureshi, S.; Thomas, S. (2020). Testing the Influence of Message Framing, Donation Magnitude, and Product Category in a cause-related Marketing Context. Journal of Marketing Communications, v. 26, n. 3, 268-289. https://doi.org/10.1080/13527266.2018.1528475

Laboratorio de Cibermetría del Consejo Superior de Investigaciones Científicas (2018). Ranking web of Universities. $\underline{U R L}$

Li, D.; Gallarza Granizo, M.; Fayos Gardó, T. (2016). The Value Trade-Off in Higher Education Service: A Qualitative Intercultural Approach to Students' Perceptions. Intangible Capital, v. 12, n. 4, 855880. http://dx.doi.org/10.3926/ic.706

Llorente Alonso, C. (2017). Marketing educativo: captación y fidelización de alumnos. ESIC Editorial. 
Manes, J. M. (2004). Marketing para instituciones educativas: guía para planificar la captación y retención de alumnos. Ediciones Granica.

Marcano Aular, Y.; Fernandez, G.; Perez, D. (2009). Diagnóstico de la Mezcla de Promoción de los Programas de Posgrado en las Universidades Públicas del Estado Falcón. Revista Venezolana de Gerencia, v. 14, n. 47, 428-444. URL

Martín-Santana, J. D.; Olarte, C.; Reinares-Lara, E.; Reinares-Lara, P.; Samino-García, R. (2019). Gestión de la comunicación: un enfoque integral. ESIC Editorial.

Melchiorre, M. M.; Johnson, S. A. (2017). Finding New Ways to Reach Older Students: Creating a Social Media Marketing Plan for Professional and Continuing Higher Education Programs. The Journal of Continuing Higher Education, v. 65, n. 2, 73-81. https://doi.org/10.1080/07377363.2017.1320178

Montoya-Robles, M. J. (2018). Comunicación organizacional: revisión de su concepto y prácticas de algunos autores mexicanos. Razón y Palabra, v. 22, n. 1_100, 778-795. URL

Olvera-Lobo, M. D.; Aguilar-Soto, M. (2011). Los sitios web académicos con información de postgrado: herramientas para su evaluación. Investigación bibliotecológica, v. 25, n. 53, 31-57. http://dx.doi.org/10.22201/iibi.0187358xp.2011.53.27468

Oplatka, I. (2017). Principal Workload: Components, Determinants and Coping Strategies in an Era of Standardization and Accountability. Journal of Educational Administration, v. 55, n. 5, 552-568. https://doi.org/10.1108/JEA-06-2016-0071

Oplatka, I. (2018). Understanding Emotion in Educational and Service Organizations Through SemiStructured Interviews: Some Conceptual and Practical Insights. The Qualitative Report, v. 23, n. 6, 1347-1363. URL

Oplatka, I.; Hemsley-Brown, J. (2007). The incorporation of market orientation in the school culture: An essential aspect of school marketing. International Journal of Educational Management, $v$. 21, n. 4, 292-305. https://doi.org/10.1108/09513540710749519

Oplatka, I.; Hemsley-Brown, J. (2012). The Research on School Marketing: Current Issues and Future Directions - An updated version. En J. Hemsley-Brown \& I. Oplatka (Eds.), The Management and Leadership of Educational Marketing: Research, Practice and Applications (Advances in Educational Administration, v. 15) (3-35). Emerald Group Publishing. https://doi.org/10.1108/S1479-3660(2012)0000015003

Ospina Díaz, M. R.; Sanabria Rangel, P. E. (2010). Un enfoque de mercadeo de servicios educativos para la gestión de las organizaciones de educación superior en Colombia: el modelo migme. Revista Facultad de Ciencias Económicas, v. 18, n. 2, 107-136. https://doi.org/10.18359/rfce.2275 
Papic Domínguez, K. (2019). Los tipos de comunicación organizacional interna en establecimientos educacionales municipalizados en Chile. Cuadernos de Investigación Educativa, v. 10, n. 1, 6383. https://doi.org/10.18861/cied.2019.10.1.2881

Pilco Mosquera, W. E. (2017). Estrategias de marketing universitario en el fortalecimiento y posicionamiento de la calidad educativa de las universidades públicas y su implicancia en el desarrollo sustentable y sostenible de la sociedad ecuatoriana (Tesis de grado). $\underline{\mathrm{UR}}$

Poole, S. M. (2017). Developing Relationships with School Customers: The Role of Market Orientation. International Journal of Educational Management, v. 31, n. 7, 1054-1068. https://doi.org/10.1108/IJEM-08-2016-0171

Sabino, C. (1992). El proceso de investigación. Editorial Panapo.

Sosa Tota, A. S.; Useche Aguirre, M. C. (2017). Marketing digital en universidades privadas en el estado Zulia. Poliantea, v. 13, n. 24, 5-26. URL

Stachowski, C. A. (2011). Educational Marketing: A Review and Implications for Supporting Practice in Tertiary Education. Educational Management Administration \& Leadership, v. 39, n. 2, 186204. https://doi.org/10.1177\%2F1741143210390056

Tranfield, D.; Denyer, D.; Smart, P. (2003). Towards a Methodology for Developing Evidence-Informed Management Knowledge by Means of Systematic Review. British Journal of Management, v. 14, n. 3, 207-222. https://doi.org/10.1111/1467-8551.00375

Uribe Saavedra, F.; Rialp Criado, J.; Llonch Andreu, J. (2013). El uso de las redes sociales digitales como herramienta de marketing en el desempeño empresarial. Cuadernos de Administración, v. 26, n. $47,205-231 . \underline{U R L}$

Vallet Bellmunt, T.; Frasquet Deltoro, M. (2005). Auge y declive del marketing-mix. Evolución y debate sobre el concepto. Esic Market, n. 121, 141-167. URL

Von Sprecher, R. H; Boito, M. E. (2010). Comunicación y trabajo social. Editorial Brujas.

World Wide Web Consortium. (2009). Pautas de accesibilidad para el contenido web (WCAG) 2.0. URL

Zapata, E. (2000). Mercadeo educativo. ¿cómo promover la oferta de instituciones y programas? Revista Colombiana de Marketing, v. 1, n. 1, 484-504. 